\title{
Insulin-like Growth Factor Binding Protein-3 (IGFBP-3) Measurements in the Diagnosis of Growth Hormone Insufficiency and Comparison with IGF- I Measurements
}

\author{
Yukihiro Hasegawa, Tomonobu Hasegawa, Shinobu Kotoh and Yutaka Tsuchiya \\ Division of Endocrinology and Metabolism, Tokyo Metropolitan Kiyose Children's Hospital, \\ Tokyo, Japan
}

\begin{abstract}
To analyze the utility of insulin-like growth factor binding protein-3 (IGFBP-3) radioimmunoassay in the diagnosis of GH insufficiency (GHI) and compare the results of IGFBP-3 and IGF- I, we measured IGF- I and IGFBP-3 in sera from normal children $(n=309)$, short children ( $n$ =99) and patients with GHI ( $n=73)$. We divided the GHI group into two groups (complete and partial GHD) and divided all the patients into two groups depending upon age (less than and older than 10 years).

The sensitivity of IGF- I for complete GHD (cGHD) was $80 \%$, while the specificity for normal short children (NS) was $81 \%$. The sensitivity of IGFBP-3 for cGHD was $93 \%$, while the specificity for NS was $88 \%$. In contrast, the sensitivities of IGF- I and IGFBP-3 for partial GHD (pGHD) were both only $43 \%$. The poor discrimination between patients with pGHD and NS by using these two parameters may be the result of their relatively similar GH level, as compared to cGHD, or of the limitations of $\mathrm{GH}$ stimulation tests in the diagnosis of GHI.

The specificities of IGF- I and IGFBP-3 for NS were high (82-92\%) in children of all ages. The sensitivity of IGF- I for GHD at less than and older than 10 years old was $66 \%$ and $71 \%$, respectively. The sensitivity of IGFBP-3 for GHI was good for children less than 10 years of age (84\%) but poor for children older than 10 years (64\%), because IGFBP-3 levels may also increase during puberty by mechanisms independent of the GH-IGF- I axis. Thus, in the younger children, the sensitivity for GHI of IGFBP-3 was higher than that of IGF- I .

Finally, although nice correlation was observed between IGFBP-3 and IGF-I levels, some patients (both GHI and NS) had discordant results of IGFBP-3 and IGF- I either below or above the cutoff levels, possibly due to limitations of GHI diagnosis based upon GH stimulation tests.
\end{abstract}

Key words: IGF- I , IGFBP-3, GH, growth hormone deficiency (GHD), normal short children (NS)

Correspondence: Dr. Yukihiro Ilasegawa, Division of Endocrinology and Metabolism, Tokyo Metropolitan Kiyose Children's Hospital, 1-3-1, Ume\%ono, Kiyose, Tokyo 204 Japan

\section{Introduction}

Insulin-like growth factor- I (IGF- I) is well known to be GH-dependent $[1,2]$ and 
useful in the diagnosis of growth hormone insufficiency (GHI) [1,2]. Recently one of the IGF binding proteins (IGFBPs), IGFBP-3 has been reported to be a major binding protein in serum and is considered to be GH-IGF-I axis dependent [3-9]. We have already reported on the usefulness and limitation of IGFBP-3 measurement in the diagnosis of GHI [10-12].

In this study, we measured both serum IGF-I and IGFBP-3 levels by RIA in sera of normal children, of normal short children (NS) and from patients with GHI to analyse the clinical utility of IGFBP-3 and to compare those two parameters as a diagnostic marker for GHI.

\section{Method and Subjects}

\section{Methods:}

1) IGF- I was measured in duplicate using a commercially available RIA kit (Medgenix and Chiba Corning) [13]. The samples were measured after acid-ethanol extraction. The sensitivity of the assay was $10 \mathrm{ng} / \mathrm{ml}$ and half-maximal displacement occurred at $5 \mathrm{ng} /$ $\mathrm{ml}$. The intraassay variation was $8-10 \%$ at $50 \mathrm{ng} / \mathrm{ml}$ and $6-8 \%$ at $100-600 \mathrm{ng} / \mathrm{ml}$. The interassay variation was $14.7 \%$ at $40 \mathrm{ng} / \mathrm{ml}, 4$. $3 \%$ at $200 \mathrm{ng} / \mathrm{ml}, 6.2 \%$ at $500 \mathrm{ng} / \mathrm{ml}$.

2) IGFBP-3 was measured as reported previously $[12,14]$. The measurement was basically similar to the one reported by Blum and Ranke in their previous report [7]. We added EDTA and protease inhibitor to the assay buffer $[12,14]$ in case IGFBP-3 (standard or samples) might be degraded by protease, which has been reported especially in sera during pregnancy $[15,16]$.

3) $\mathrm{GH}$ was measured by various RIA or IRMA assays. The definition of $\mathrm{GHI}$ and NS (defined later) was determined after the $\mathrm{GH}$ levels were calculated into our IRMA (Eiken kit) at Tokyo Metropolitan Kiyose Children's Hospital, according to the relations between various $\mathrm{GH}$ assays determined by the Japanese Growth Foundation and our own hospital [17].
Subjects: All were Japanese

1) Normal control adults $(n=33$, age 18-40) and children ( $n=309$, age 1 month-17 years) participated in this study at Tokyo Metropolitan Kiyose Children's Hospital. The heights of the control persons were within mean $\pm 2 \mathrm{SD}$. Informed consent was obtained at the hospital.

2) Seventy-three patients with GHI (43 complete $\mathrm{GHD}$ and 30 partial GHD, which we define later precisely) and 99 patients with NS (height $<-2 \mathrm{SD}$ ) were also involved in this study. About $50 \%$ of the patients had been followed at Tokyo Metropolitan Kiyose Children's Hospital. Among 73 patients with GHI, 54 were idiopathic GHI and 19 were secondary GHI due to other diseases such as brain tumor, radiation, etc. The associated hormonal deficiencies were treated appropriately with thyroxine, hydrocortisone and antidiuretic hormone. Secondary hypogonadism was not treated in this study.

The GHI patients were subdivided into two groups, namely complete GHD (cGHD) and partial GHD (pGHD). The definition of cGHD, pGHD and NS were the following: cGHD: all the $\mathrm{GH}$ peaks of $\mathrm{GH}$ stimulation tests (usually arginine and insulin tolerance tests) are less than $5 \mathrm{ng} / \mathrm{ml}$, pGHD: the highest $\mathrm{GH}$ peak of $\mathrm{GH}$ stimulation tests (usually arginine and insulin tolerance tests) is from 5 to $10 \mathrm{ng} / \mathrm{ml}$, NS: at least one $\mathrm{GH}$ peak of $\mathrm{GH}$ stimulation tests is more than $10 \mathrm{ng} / \mathrm{ml}$. GH stimulation tests were done at least twice. These definitions of GHI and NS are basically similar to those in Blum and Ranke's paper [7] and the same as in our previous paper [12]. The false positive ratio of arginine and insulin tolerance tests at Tokyo Metropolitan Kiyose Children's Hospital [17] was 22-23\% in short children. IGF-I and IGFBP-3 levels of GHI were measured either before GH therapy was started or after GH therapy was discontinued. All the samples (serum or plasma) were kept at $-80^{\circ} \mathrm{C}$ or $-110^{\circ} \mathrm{C}$ for less than 1 year.

Statistics: All data are shown as the mean \pm 


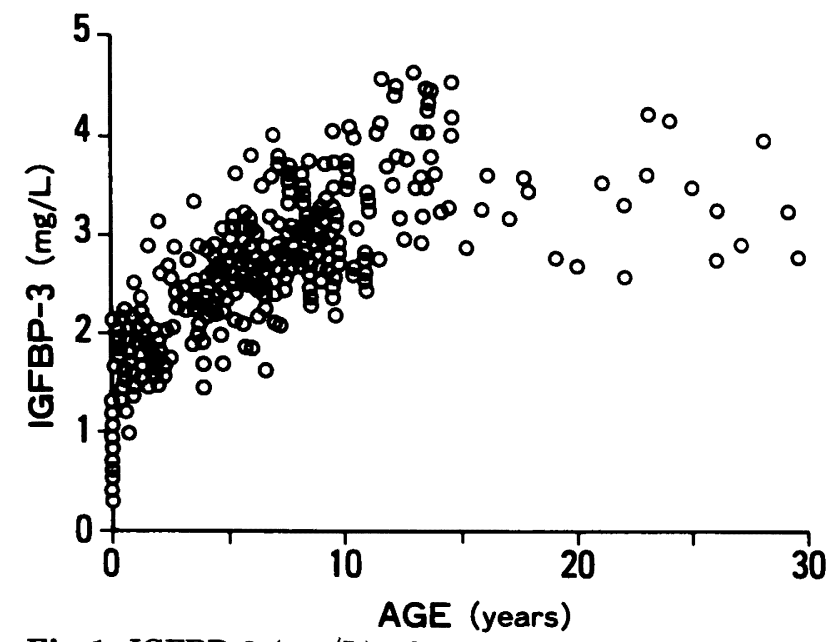

Fig 1. IGFBP.3 (mg/L) of normal control children.

SD. Statistical comparisons were made by Mann-Whitney $U$ analysis and Chi square analysis.

\section{Results}

\section{IGFBP-3}

1) Figure 1 shows normal IGFBP-3 levels. There was no significant difference between females and males except for the age of six to eight. We set cutoff levels based upon mean -2 SD (Table 1).

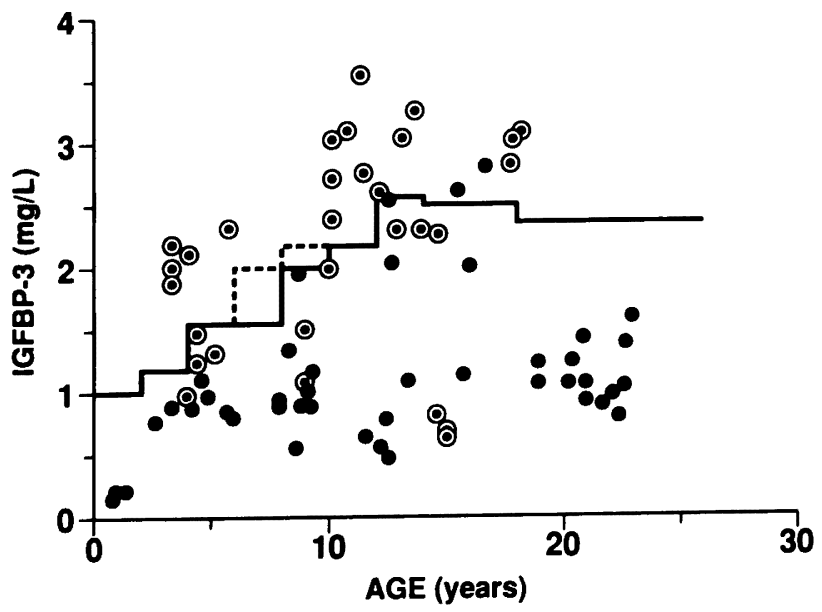

Fig 2. IGFBP-3 (mg/L) of patients with GHI. The lines are the cutoff levels at each age and sex. The dotted line means the cutoff levels only for female children. Closed circle $(O)$ and double circle $(\odot)$ mean cGHD and pGHD, respectively.

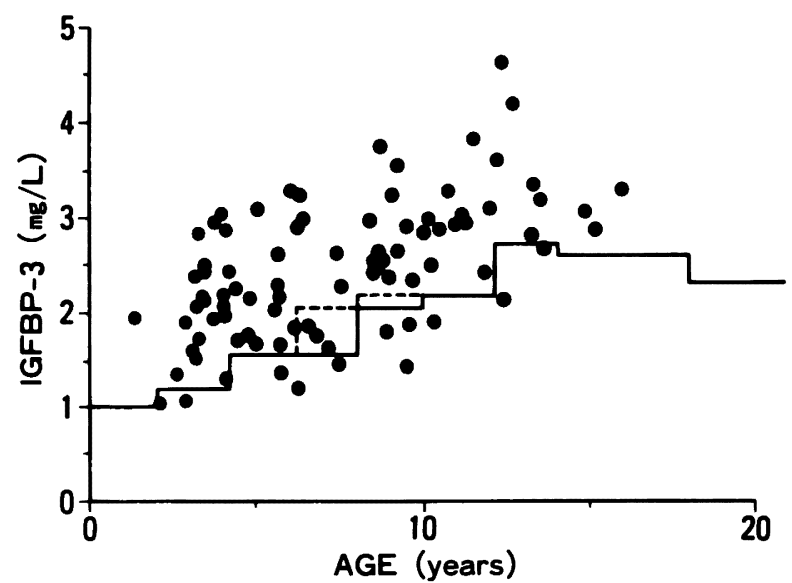

Fig 3. IGFBP-3 (mg/L) of patients with NS. The lines are the cutoff levels at each age and sex. The dotted line means the cutoff levels only for female children.

2) Figure 2 shows IGFBP-3 levels of patients with GHI, together with the cutoff levels. The IGFBP-3 of cGHD was almost always less than the cutoff levels, whereas the IGFBP-3 of pGHD was sometimes more than the cutoff levels. If we determine the sensitivity using these cutoff levels, the sensitivities of cGHD and pGHD were $93 \%$ and $43 \%$, respectively.

3) Figure 3 shows IGFBP-3 levels of NS. The specificity for NS was $88 \%$.

4) Table 2 shows the sensitivity and specificity of IGFBP-3 in the under and over 10 year old groups of GHI and NS. The specificity in the younger ages was quite similar to that in the older ages ( $87 \%$ and $88 \%$ ), whereas the sensitivity of GHI was higher in the younger ages (84\%) than in the older ages (64\%), although there was no statistical difference in the sensitivity between the younger and the older ages. The same difference between the younger and older ages was true in patients with either cGHD or pGHD.

5) In order to analyse the difference between the younger and older ages, we studied IGFBP-3 of older GHI patients (15-24 years old) in whom we have proved whether secondary hypogonadism was associated or not. One out of 12 (7 cGHD and 5pGHD) GHI patients with secondary hypogonadism showed an IGFBP-3 level above the cutoff 
levels. By contrast, nine out of $10 \mathrm{GHI}$ patients ( 3 cGHD and 7 pGHD) without secondary hypogonadism showed an IGFBP-3 level above the cutoff levels, and there was a statistical difference in the ratio of the GHI patients whose IGFBP-3 levels were above the cutoff levels between patients with hypogonadism and without hypogonadism $(p<0.01)$. This difference suggests that gonadal steroids may increase IGFBP-3 levels during puberty, possibly independently of the GH-IGF-I axis.

\section{Comparison of IGFBP-3 results with IGF- I results}

1) Table 1 also shows normal IGF- I levels and cutoff levels, which were determined by the 5 th percentile of normal control children for each age and sex.

2) Quite similarly to the IGFP-3 study, the sensitivity and specificity were determined (Table 2). The results of IGF-I, namely, high sensitivity for cGHD, low sensitivity for pGHD, and high specificity for NS at all ages were similar to the IGFBP-3 results. However, there was almost no difference in the sensitivity of IGF-I for GHI between the younger and older groups (about $70 \%$ ), and thus, in the younger ages, the IGF- I sensitivity was lower than the IGFBP-3 sensitivity, although there was no statistical difference in the younger ages between IGF-I sensitivity and IGFBP-3 sensitivity.

3) We studied further the relation between IGFBP-3 and IGF. I . There was a significant correlation between IGFBP-3 and IGF. I ( $\mathrm{n}=$ 238, $\mathrm{r}=0.74, \mathrm{p}<0.0005)$. However, when we looked at these two values in individual patients, there were some patients with GHI in whom either IGFBP-3 or IGF-I was more than the cutoff levels, which we call here discordant results of IGFBP-3 and IGF-I . Actually, 25\% (18/73) of patients with GHI and $19 \%(18 / 93)$ of those with NS had discordant results of IGFBP-3 and IGF-I either below or above the cutoff levels. In GHI patients, the discordant ratio was higher in pGHD (47\%) than in cGHD $(9 \%)$, which is
Table 1: Normal and cutoff levels of IGF. I (ng/ml) and IGFBP-3 (mg/L). M and F mean male and female, respectively.

\begin{tabular}{lcccc}
\hline & \multicolumn{2}{c}{ IGF. I $(\mathrm{ng} / \mathrm{ml})$} & \multicolumn{2}{c}{ IGFBP-3 (mg/L) } \\
mean \pm SD & cutoff & mean \pm SD & cutoff \\
$1 \mathrm{M}-2 \mathrm{Y}$ & $85 \pm 40$ & 40 & $1.80 \pm 0.39$ & 1.0 \\
$2 \mathrm{Y}-4 \mathrm{Y}$ & $104 \pm 47$ & 50 & $2.22 \pm 0.45$ & 1.2 \\
$4 \mathrm{Y}-6 \mathrm{Y}$ & $158 \pm 56$ & 60 & $2.66 \pm 0.43$ & 1.6 \\
$6 \mathrm{Y}-8 \mathrm{Y}$ & $195 \pm 61$ & 120 & $\mathrm{M} 2.67 \pm 0.53$ & 1.6 \\
& & & $\mathrm{~F} 3.00 \pm 0.50$ & 2.0 \\
$8 \mathrm{Y}-10 \mathrm{Y}$ & $\mathrm{M} 220 \pm 73$ & 140 & $\mathrm{M} 2.98 \pm 0.49$ & 2.0 \\
& $\mathrm{~F} 259 \pm 60$ & 160 & $\mathrm{~F} 3.10 \pm 0.46$ & 2.2 \\
$10 \mathrm{Y}-12 \mathrm{Y}$ & $355 \pm 142$ & 160 & $3.42 \pm 0.60$ & 2.2 \\
$12 \mathrm{Y}-14 \mathrm{Y}$ & $442 \pm 140$ & 180 & $3.88 \pm 0.59$ & 2.7 \\
$14 \mathrm{Y}-18 \mathrm{Y}$ & $438 \pm 131$ & 180 & $3.55 \pm 0.49$ & 2.6 \\
$18 \mathrm{Y}-40 \mathrm{Y}$ & $301 \pm 116$ & 160 & $3.25 \pm 0.49$ & 2.3 \\
\hline
\end{tabular}

Table 2: Sensitivity (\%) and specificity (\%) of IGF- I and IGFBP- 3 in the younger $(<10$ years old $)$ and in the older ( $>10$ years old) groups.

\begin{tabular}{|c|c|c|c|c|c|c|}
\hline & \multicolumn{3}{|c|}{ IGF - I } & \multicolumn{3}{|c|}{ IGFBP-3 } \\
\hline & $<10 \mathrm{Y}$ & $>10 Y$ & total & $<10 Y$ & $>10 \mathrm{Y}$ & total \\
\hline $\begin{array}{l}\text { GHD sensitiv- } \\
\text { ity (\%) } \\
\text { (cGHD+ } \\
\text { pGHD) }\end{array}$ & $\begin{array}{c}65 \\
(n=31)\end{array}$ & $\begin{array}{c}71 \\
(n=42)\end{array}$ & $\begin{array}{c}68 \\
(n=73)\end{array}$ & $\begin{array}{c}84 \\
(n=31)\end{array}$ & $\begin{array}{c}64 \\
(n=42)\end{array}$ & $\begin{array}{c}73 \\
(n=73)\end{array}$ \\
\hline $\begin{array}{l}\text { cGHD sensi- } \\
\text { tivity }(\%)\end{array}$ & $\begin{array}{c}79 \\
(n=19) \\
\end{array}$ & $\begin{array}{c}92 \\
(n=24)\end{array}$ & $\begin{array}{c}86 \\
(n=43)\end{array}$ & $\begin{array}{c}100 \\
(n=19)\end{array}$ & $\begin{array}{c}88 \\
(n=24)\end{array}$ & $\begin{array}{c}93 \\
(n=43)\end{array}$ \\
\hline $\begin{array}{l}\text { pGHD sensi- } \\
\text { tivity (\%) }\end{array}$ & $\begin{array}{c}42 \\
(n=12)\end{array}$ & $\begin{array}{c}44 \\
(n=18)\end{array}$ & $\begin{array}{c}43 \\
(n=30)\end{array}$ & $\begin{array}{c}58 \\
(n=12)\end{array}$ & $\begin{array}{c}33 \\
(n=18)\end{array}$ & $\begin{array}{c}43 \\
(n=30)\end{array}$ \\
\hline $\begin{array}{l}\text { NS } \\
\text { specificity } \\
(\%)\end{array}$ & $\begin{array}{c}82 \\
(n=71)\end{array}$ & $\begin{array}{c}86 \\
(n=28)\end{array}$ & $\begin{array}{c}83 \\
(n=99)\end{array}$ & $\begin{array}{c}87 \\
(n=69)\end{array}$ & $\begin{array}{c}88 \\
(n=24)\end{array}$ & $\begin{array}{c}88 \\
(n=93)\end{array}$ \\
\hline
\end{tabular}

significant $(p<0.001)$. This difference in the discordant ratio between cGHD and pGHD maybe reflects the limitation of $\mathrm{GH}$ stimulation tests in the diagnosis of GHI.

\section{New subdivision of pGHD (probable and possible pGHD)}

Finally, to solve the limitations of the GH stimulation tests in the diagnosis for GHI and to analyse more clearly the utility of IGFBP-3, we have set a new subgroup using the results of IGF- I results in addition to those of $\mathrm{GH}$ stimulation tests. Formerly we divided GHI into two subgroups, namely cGHD and pGHD. Here we subdivide pGHD into two 
subtypes, namely probable and possible pGHD. Probable pGHD patients had the same range of the highest $\mathrm{GH}$ peak during $\mathrm{GH}$ stimulation tests as we defined for pGHD (from 5 to $10 \mathrm{ng} / \mathrm{ml}$ ) and low IGF- I level (less than 5th percentile). Possible pGHD patients had the same range of the highest GH peak and normal IGF. I levels (more than 5th percentile). If we use these new subgroups, the sensitivities of probable and possible pGHD were $64 \%(n=14)$ and $25 \%(n=16)$, respectively. There was a statistical difference in the sensitivity between probable and possible pGHD $(p<0.05)$. In the under 10 year old group, which is a more homogeneous group, the sensitivities of probable and possible pGHD were $83 \%(n=6)$ and $33 \%(n=6)$, respectively.

\section{Discussion}

The specificity of both IGF- I and IGFBP3 for the diagnosis of GHI was about $80-90 \%$ at all ages. The sensitivity of IGFBP-3 and IGFI for cGHD was also high (about $80-90 \%$ ) at all ages. Thus, both IGF- I and IGFBP-3 are useful for screening GHI at any age.

IGF-I and IGFBP-3 measurements for the diagnosis of pGHD are not so useful as for cGHD. The sensitivity of IGFBP-3 for pGHD was much lower than that reported by Blum et al. [7], although they did not classify GHD into two types as we did into cGHD and pGHD. One reason for the difference in the usefulness of IGF- I and IGFBP-3 between cGHD and pGHD is easy to understand, since the severity of deficiency is greater in cGHD than in pGHD, by definition.

Another possibility for lower sensitivity in pGHD than in cGHD is the limitation of $\mathrm{GH}$ stimulation tests including poor reproducibility [17-19]. The limitations of $\mathrm{GH}$ stimulation tests were analysed clearly by dividing the group of pGHD into two subtypes depending upon IGF- I levels (probable and possible pGHD). The fact that there was a difference of sensitivity between probable and possible pGHD suggested that there was a wide clinical spectrum in pGHD (from the relatively severe GHI to the less severe GHI) if we define pGHD only based upon the results of $\mathrm{GH}$ stimulation tests.

IGFBP-3 may reflect GH secretion status. The results of the sensitivity of possible pGHD (normal IGF- I group) suggested that IGFBP. 3 levels were not so low in the less severe types of GHI. The sensitivity of probable pGHD, taken together with that of cGHD, suggested that IGFBP-3 sensitivity was high in the severe types of GHI. Because there are some limitations of $\mathrm{GH}$ stimulation tests in the diagnosis of GHI, diagnosis based on not only results of GH stimulation tests but also those of other IGF parameters such as serum IGF- I and IGFBP-3 level, which probably reflect GH secretion status, will be another way of diagnosis in the near future.

The sesitivity of IGF. I in our younger GHI patients $(66 \%,<10$ years) was similar to our older GHI patients $(71 \%,>10$ years) whereas the sensitivity of IGFBP-3 in the younger GHI patients ( $84 \%,<10$ years) was higher than in the older GHI patients $(64 \%,>$ 10 years). The higher sensitivity of IGFBP-3 in the younger than in the older GHI patients may be explained by the pubertal increase in IGFBP-3 which is independent of the GH-IGFI axis [11,12], judging from our study of IGFBP-3 using GHI patients with or without secondary hypogonadism (result (5)).

Although the correlations between IGF- I and IGFBP-3 were very nice, among our subjects with GHI and NS there were $19-25 \%$ (18/73 in GHD, 18/93 in NS) of the subjects who showed discordant results of IGF. I and IGFBP-3 either below or above the cutoff levels. One speculation about the discordant results is that measuring both IGF. I and IGFBP-3 may improve sensitivity and specificity for diagnosing GHI. However, it is also important to note that both IGF. I and IGFBP-3 sensitivity for cGHD were very high in our study $(86 \%, 93 \%$, respectively). The other speculation concerning the discordant results of IGFBP-3 and IGF- I is that there is a limitation of GHI diagnosis, based upon 
results of GH stimulation tests. This speculation has to be considered because the discordant ratio was higher in pGHD than in cGHD. Furthermore, the IGFBP-3 sensitivity for probable pGHD was higher than that for possible pGHD, as we have described before.

\section{Acknowledgement}

We are greatly indebted for the technical assistance given by Ms. Miyuki Toyama and Mr. Fumihiko Kurimoto (Mitsubishi Yuka BCL, Tokyo, Japan). This work was supported in part by the Sumitomo Pharmaceutical Fund (Osaka, Japan).

\section{References}

1. Nissley S, Rechler M. Insulin-like growth factors: biosynthesis, receptors, and carrier proteins. In: Li CH (ed) Hormonal proteins and peptides XII. Academic Press, New York, 1985; 128-203.

2. Daughaday W, Rotwein P. Insulin-like growth factors I and II. Peptides, messenger ribonucleic acid and gene structures, serum and tissue concentrations. Endo Reviews 1989; 10: 68-91.

3. Rosenfeld RG, Lamson G, Pham $H$, et al. Insulin-like growth factor binding proteins. Rec Prog Horm Res. 1991; 46: 99-117.

4. Hardouin S, Gourmelen M, Noguiez P, et al. Molecular forms of serum insulin-like growth factor binding proteins in man: relationships with growth hormone and IGFs and physiological significance. J Clin Endocrinol Metab 1989; 69: 1291-301.

5. Hintz R, Liu F, Rosenfeld R, Kemp S. Plasma somatomedin-binding proteins in hypopituitarism: changes during growth hormone therapy. J Clin Endocrinol Metab 1981; 53: 100-4.

6. Rosenbloom AL, Aguirre JG, Rosenfeld RG, Fielder PJ. The little women of Loja - growth hormone-receptor deficiency in an inbred population of southern Ecuador.
N Engl J Med 1990; 323: 1367-74.

7. Blum WF, Ranke MB, Kietzmann K, Gauggel E, Zeisei HJ, Bierich JR. A specific radioimmunoassay for the growth hormone-dependent somatomedin-binding protein: its use for diagnosis of $\mathrm{GH}$ deficiency. J Clin Endocrinol Metab 1990; 70: 1292-8.

8. Martha PM, Reiter EO, Blizzard RM, Stene $\mathrm{M}$, Veldhuis JD and Rogol AD. The maturity-related rise of IGFBP-3 concentration. Pediatric Research (Abstract) 1991; 473: 81A.

9. Phillip M, Chalew SA, Kowarski AA, Stene M. Insulin-like growth factor binding protein-3 concentrations in poorly growing children. The Endocrine Society (Abstract) 1991; 145: 460.

10. Cohen P, Fielder PJ, Hasegawa Y, Frisch H, Guidice LC, Rosenfeld RG. Clinical aspects of insulin-like growth factor binding proteins. Acta Endocrinol [Copenh]. 1991; 124: 74-85.

11. Hasegawa Y, Hasegawa T, Yokoyama T, Kotoh S, Tsuchiya $\mathrm{Y}$ and Kurimoto F. Western Ligand Blot-assay for human growth hormone-dependent insulin-like growth factor binding protein (IGFBP-3) … The serum levels in patients with classical growth hormone deficiency. Endocrinol Japon 1992; 39(1): 121-7.

12. Hasegawa $Y$, Hasegawa $T$, Aso T, Kotoh S, Tsuchiya Y, Nose O, Ohyama Y, Araki K, Tanaka T, Saisyo S, Yokoya S, Nishi Y, Miyamoto S, Sasaki N, Stene M. Usefulness and limitation of measurement of IGFBP-3 for diagnosis of growth hormone deficiency. Endocrinol Japan 1992; 39(6): 585-91.

13. Hasegawa Y, Hasegawa T, Yokoyama T, Kotoh S, Tsuchiya Y, Nose O, et al. Usefulness of IGF. I measurement (after acid extraction) for diagnosis of growth hormone deficiency. Horumon-to-Rinsyou 1992; 40(10): 1107-10 (in Japanese).

14. Toyama M, Kurimoto F, Hasegawa Y, Hasegawa T, Kotoh S, Tsuchiya Y. Methodology of IGFBP-3 RIA. Horumone-to- 
Rinsyou 1992; 40(10): 1085-90 (in Japanese). 15. Hossenlopp P, Segovia B, Lassarre C, Roghani M, Bredon M. Binoux M. Evidence of enzymatic degradation of insulinlike growth factor binding proteins in the "150 k" complex during pregnancy. J Clin Endo Metab 1990; 71: 797-805.

16. Guidice LC, Farrell EM, Pham H, Lamson G, Rosenfeld RG. Insulin-like growth factor binding proteins in maternal serum throughout gestation and in the puerperium: Effects of a pregnancy-associated serum protease activity. J Clin Endo Metab 1990; 71: 806-16.

17. Hasegawa Y, Hasegawa T, Kotoh S, Tsu- chiya Y. False positive ratios of GH provocation tests (arginine and insulin) in control and normal short children. Clin Pediatr Endocrinol (in print).

18. Hasegawa Y, Hasegawa T, Kotoh S, Tsuchiya Y. Reproducibility of GH provocation tests (arginine and insulin), IGF- I levels and IGFBP-3 measurements. Clin Pediatr Endocrinol (in print).

19. Donaldson DL, Pan F, Hollowell JG, Stevenson JL, Gifford RA, and Moore WV. Reliability of stimulated and spontaneous growth hormone $(\mathrm{GH})$ levels for identifying the child with low GH secretion. J Clin Endocrinol Metab 1991; 72: 647-52. 